Research Article

\section{Collection and evaluation of indigenous buck semen at the coastal region of Bangladesh}

\author{
Mahfuza Swarna1, Nani Gopal Saha², Sukanta Biswas ${ }^{1}$ and \\ Ashit Kumar Paul ${ }^{1 *}$ \\ 'Department of Medicine, Surgery and Obstetrics, Patuakhali Science and Technology University, \\ Outer Campus, Babugonj, Barishal-8210, Bangladesh \\ ${ }^{2}$ Department of Animal Science and Animal Nutrition, Faculty of Animal Science and Veterinary \\ Medicine, Patuakhali Science and Technology University, Outer Campus, Babugonj, Barishal-8210, \\ Bangladesh
}

\section{Abstract}

Evaluation of semen characteristics is an important and prior for semen preservation. The aim of this study was to collection and evaluation of indigenous buck semen in the coastal region of Bangladesh. The semen was collected from bucks through artificial vagina method. The colour, odour, volume, viscosity, mass activity, consistency, concentration and individual sperm motility were analysed and recorded after collection from pre-selected four bucks. The colour and odour of all buck (B) semen were creamy white to milky white and fishy smell, respectively. In this study, we found that the average volume of B-1, B-2, B-3 and B-4 were $0.74,0.98,0.42$ and $0.60 \mathrm{ml}$, respectively. The average grading of viscosity of B-1, B-2, B-3 and B-4 were 3.2, 3.8, 2.6 and 3.0 , respectively. The average grading of mass activity of B-1, B-2, B-3 and B-4 were 3.6, 3.2, 2.4 and 3.4, respectively. The consistency of B-1, B-2, B-3 and B-4 were 4.2, 4.8, 2.8 and 4.0, respectively. The concentration of $\mathrm{B}-1, \mathrm{~B}-2, \mathrm{~B}-3$ and $\mathrm{B}-4$ were $1.58,1.94,0.62$ and $1.54 \times 109$ per $\mathrm{ml}$ of semen volume. The average percentage of individual sperm motility of B-1, B-2, B-3 and B-4 were $81,71,66$ and $80 \%$, respectively. Viscosity, mass activity, consistency, concentration and individual sperm motility were significantly $(p<0.05)$ correlate with each other. It may be concluded that the data about semen of the bucks are in acceptable level for preservation. Further study will be designed for the evaluation of viability and motility of sperm before and after freezing as liquid semen.

\section{More Information}

*Address for Correspondence: Ashit Kumar Paul, Department of Medicine, Surgery and Obstetrics, Patuakhali Science and Technology University, Outer Campus, Babugonj, Barishal-8210, Bangladesh, Email: akpaul2008@gmail.com

Submitted: December 27, 2021

Approved: January 11, 2022

Published: January 12, 2022

How to cite this article: Swarna M, Saha NG, Biswas S, Paul AK. Collection and evaluation of indigenous buck semen at the coastal region of Bangladesh. Insights Vet Sci. 2022; 6: 001-004.

DOI: 10.29328/journal.ivs.1001034

Copyright License: ๔ 2022 Swarna M, et al. This is an open access article distributed under the Creative Commons Attribution License, which permits unrestricted use, distribution, and reproduction in any medium, provided the original work is properly cited.

Keywords: Bucks; Coastal area; Semen; Rvaluation

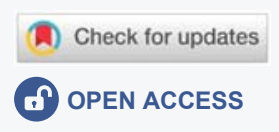

\section{Introduction}

Goat farming is rising in Bangladesh as small and medium scale due to huge meat demand. It is also reared integrally with other farming systems. The goat is reared as a traditional system at the coastal region of Bangladesh. Rural women are taking care goat beside their household works [1]. Black Bengal is the only pure breed of Bangladesh. Most of the goats (90\%) reared are Black Bengal [2], alleged for their prolificacy, fertility, early sexual maturity, adaptability to hot humid conditions and superior quality meat and skin $[2,3]$. The non-descriptive local goat breed bears some unique characteristics such as being adapted in humid climatic condition, saline tolerance, grazing within rain and stand over stagnant water field, Paul, et al. [1] also reported that the breed, at the coastal region, has found some dissimilarity from other parts of Bangladesh. However, the haphazard breeding system seriously abolishes these distinctive characteristics. The preservation of semen is one of the tools for breed conservation. As these breeds showed unique characteristics, therefore, the conservation of the local breed is largely important for restoring these unique genetic characteristics. The success of semen preservation is markedly dependent on the semen quality such as colour, odour, consistency, viscosity, concentration, mass activity, individual motility and viability. Artificial Vagina (AV) method is a proven method of semen collection from bucks for analysis and preservation [4]. In our previous study, we have selected bucks according to their fertility [1]. The assessment of semen quality is prerequisite for semen cryopreservation. As we are committed to conserving semen of these unique breed, in further study, therefore semen evaluation is mandatory. 
However, there is no published data of semen analysis of these breed at the coastal region. The objective of present study is to collect and evaluate buck semen to proceed for semen cryopreservation.

\section{Materials and methods}

\section{Study place}

The study was conducted at the Theriogenology and Animal Reproductive Biotechnology laboratory, Department of Medicine, Surgery and Obstetrics, Faculty of Animal Science and Veterinary Medicine, Patuakhali Science and Technology University, Barishal Campus, Babugonj, Barishal. Although there is no animal ethical committee in the university, the animals used in this experiment were ethically approved by the Department of Medicine, Surgery and Obstetrics as per the law of animal welfare in Bangladesh.

\section{Management of bucks}

A total of 4 bucks were selected according to their fertility rate and observation of different parameter from our previous study [1]. The bucks were between 2-3 years old and weighing 15 to $20 \mathrm{~kg}$ with good body condition. They were maintained on natural grazing, with supplemented feeding (concentrate mixture composed of $25 \%$ crushed maize, $50 \%$ wheat bran, $20 \%$ soybean meal, $1 \%$ fish meal, $2 \%$ DCP Powder, $1.5 \%$ salt and $0.5 \%$ vitamin-mineral premix) at $250 \mathrm{~g} / \mathrm{head} /$ day. Water and a mineral salt lick were provided ad libitum. They were reared in same management system. All goats were dewormed (Renadex ${ }^{\circledR}$ Renata Animal Health, Dhaka, Bangladesh) and injected 3ml vitamin ADE (Renasol $\mathrm{AD}_{3} \mathrm{E}^{\circledR}$ Renata Animal Health, Dhaka, Bangladesh) and B-complex (Multivit ${ }^{\circledR}$ vet, Squiare Pharmaceuticals limited, Dhaka, Bangladesh) at 5 days interval for three injections before a month of semen collection. They were practised mounting in a dummy at every two days interval.

\section{Semen collection}

The semen was collected at oestrus doe mount by artificial vagina (AV) method once a week (Figure 1). The bucks were allowed at least one to two false mounts before the collection of semen. The preputial sheath of the buck was lightly grasped and deviated into the $\mathrm{AV}$ in its final mount. Immediately after collection, the collecting tube was detached from the AV,

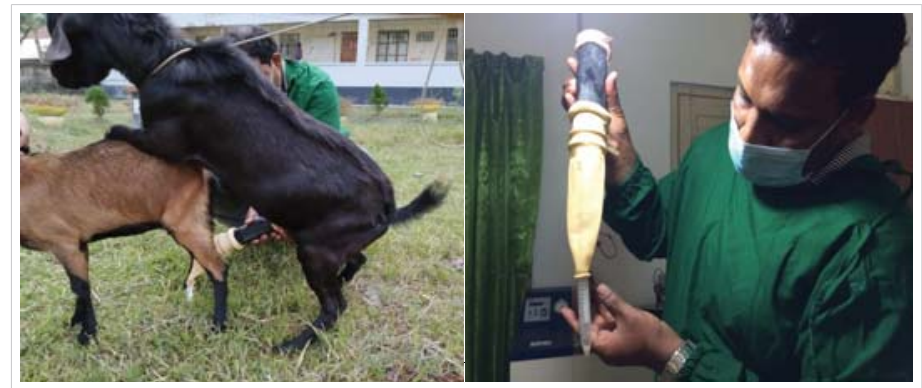

Figure 1: Semen collection from bucks by AV and semen evaluation in the lab. taken to the laboratory and placed in a water bath $\left(38.0^{\circ} \mathrm{C}\right)$ until evaluation and processing of the semen.

\section{Semen evaluation}

The routine evaluation of fresh semen was performed as described by Jainudeen, et al. [5].

Volume: The volume of fresh semen was recorded from the graduated mark of the semen collecting tube.

Colour: The colour of the semen was recorded in the collecting tube immediately after collection by naked eyes. The colour was scored into 4 scales: 1 for watery; 2 for milky white; 3 for yellowish white and 4 for creamy white.

Odour: Normal odour of semen is fishy. If any other unusual odour is noted the semen should be rejected.

\section{Consistency and sperm concentration}

The grading of consistency of semen and sperm concentration is shown in Table 1.

Viscosity: The grading of viscosity of semen is shown in Table 2.

Mass activity: To evaluate mass activity, a drop $(25 \mu \mathrm{l})$ of semen was placed on a pre-warmed $\left(+38^{\circ} \mathrm{C}\right)$ glass slide without coverslip and examined under light microscope at low magnification (100X). The mass activity was scored into 4 scales, 1 = no mass activity, 2 = slow wave motion without forming any waves, 3 = rapid wave motion with formation of eddies at the end of waves, $4=$ very rapid wave motion with distinct eddies.

Sperm motility: A drop $(10 \mu \mathrm{l})$ of semen was placed on a clean pre-warmed $\left(+38{ }^{\circ} \mathrm{C}\right)$ glass slide and covered with a coverslip. The motility was determined by eye estimation seeing the proportion of spermatozoa moving progressively straight forward at higher magnification (200X). It is indicated that the biochemical test for semen quality were not performed in these experiment. The fructose and acrosin test for ensuring sperm quality will be done in further experiments.

\begin{tabular}{|c|c|c|}
\hline \multicolumn{2}{|c|}{ Table 1: Grading of semen consistency and sperm concentration. } \\
\hline Consistency & Grading & $\begin{array}{c}\text { Approximate sperm } \\
\text { concentration (million/ml) }\end{array}$ \\
\hline Thick creamy & 5 & Over 2000 \\
\hline Creamy & 4 & $1500-2000$ \\
\hline Thin creamy & 3 & $400-800$ \\
\hline Milky & 2 & $150-350$ \\
\hline Watery & 1 & Below 150 \\
\hline
\end{tabular}

Table 2: Grading of viscosity of semen.

\begin{tabular}{|c|c|c|}
\hline Viscosity & Grading & Numbering \\
\hline Very Viscous & DDDD & 4 \\
\hline Viscous & DDD & 3 \\
\hline Slow running & DD & 2 \\
\hline Rapid running & D & 1 \\
\hline Completely running & 0 & 0 \\
\hline
\end{tabular}


Experimental layout: The experimental flowchart is shown in Figure 2.

\section{Limitation of methodology}

The method used in the experiment was a routine semen evaluation as described by different researchers. The limitation of the method is to not explore molecular characterization of sperm. However, the pros of the method is to quick analysis of semen, whereas it could not enough for sperm quality assurance. Further study will be designed to overcome these limitations.

\section{Statistical analysis}

The recorded data were entered in the Microsoft Excel sheet. The average semen volume, consistency, concentration of sperm and mass activity were calculated expressed as mean

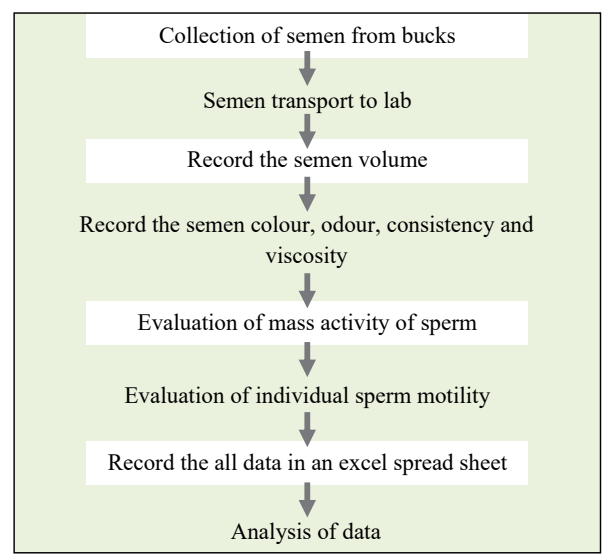

Figure 2: The experimental flowchart. \pm SD. The individual sperm motility was expressed as the average percentage. The descriptive analysis and Correlations coefficients were calculated by statistical program for social science (SPSS) software (SPSS ${ }^{\circledR}$ Version 22.0). The analysis of variance (AVOVA) was done for test the significance. In case of all parameters, a statistical significance was considered at $p \leq 0.05$.

\section{Result and discussion}

Semen was collected from pre-selected four bucks. The semen collection was repeated ten times from each buck. The semen was collected through mounting with oestrus doe once a week. The creamy-white colour of semen was considered for the evaluation of different parameters. The entire collected semen odour was fishy smell. The average volume, viscosity and mass activity of bucks had shown in Table 3 . In this study, we found that the average volume of B-1, B-2, B-3 and B-4 were $0.74,0.98,0.42$ and $0.60 \mathrm{ml}$, respectively. The four bucks belonged to the same breed and of similar age their management and nutritional status and general health condition were also similar. So, the difference in the volume of semen might reflect their different genetic potentiality and genetically superior bucks could produce higher volume of semen. The result of the present study agrees with the studies of previous workers [6-8]. Sultana, et al. [6] and Karim, (2008) also reported a significant $(p<0.05)$ individual variation on semen volume of Black Bengal bucks. The average grading of viscosity of B-1, B-2, B-3 and B-4 were 3.2, 3.8, 2.6 and 3.0, respectively. The average grading of mass activity of $\mathrm{B}-1$, B-2, B-3 and B-4 were 3.6, 3.2, 2.4 and 3.4, respectively. Raji

Table 3: Descriptive analysis of semen parameters among bucks.

\begin{tabular}{|c|c|c|c|c|c|c|c|}
\hline \multirow{2}{*}{ Variables } & \multirow{2}{*}{ Buck } & \multirow{2}{*}{$\mathbf{N}$} & \multirow{2}{*}{ Mean \pm SD } & \multicolumn{3}{|c|}{$95 \% \mathrm{CI}$ for Mean } & \multirow{2}{*}{$\begin{array}{c}p \text { - value } \\
\text { (Within and between groups) }\end{array}$} \\
\hline & & & & Lower Bound & Upper Bound & df & \\
\hline \multirow{4}{*}{ Volume } & 1 & 10 & $0.74 \pm 0.18$ & .609 & .871 & \multirow{4}{*}{14.195} & \multirow{4}{*}{0.000} \\
\hline & 2 & 10 & $0.98 \pm 0.29$ & .770 & 1.190 & & \\
\hline & 3 & 10 & $0.42 \pm 0.12$ & .332 & .508 & & \\
\hline & 4 & 10 & $0.60 \pm 0.15$ & .493 & .707 & & \\
\hline \multirow{4}{*}{ Viscosity } & 1 & 10 & $3.20 \pm 0.79$ & 2.64 & 3.76 & \multirow{4}{*}{6.618} & \multirow{4}{*}{0.001} \\
\hline & 2 & 10 & $3.80 \pm 0.42$ & 3.50 & 4.10 & & \\
\hline & 3 & 10 & $2.60 \pm 0.52$ & 2.23 & 2.97 & & \\
\hline & 4 & 10 & $3.00 \pm 0.67$ & 2.52 & 3.48 & & \\
\hline \multirow{4}{*}{ Mass activity } & 1 & 10 & $3.60 \pm 0.52$ & 3.23 & 3.97 & \multirow{4}{*}{7.781} & \multirow{4}{*}{0.000} \\
\hline & 2 & 10 & $3.20 \pm 0.42$ & 2.90 & 3.50 & & \\
\hline & 3 & 10 & $2.40 \pm 0.52$ & 2.03 & 2.77 & & \\
\hline & 4 & 10 & $3.40 \pm 0.84$ & 2.80 & 4.00 & & \\
\hline \multirow{4}{*}{ Consistency } & 1 & 10 & $4.20 \pm 0.79$ & 3.64 & 4.76 & \multirow{4}{*}{19.781} & \multirow{4}{*}{0.000} \\
\hline & 2 & 10 & $4.80 \pm 0.42$ & 4.50 & 5.10 & & \\
\hline & 3 & 10 & $2.80 \pm 0.422$ & 2.50 & 3.10 & & \\
\hline & 4 & 10 & $4.00 \pm 0.67$ & 3.52 & 4.48 & & \\
\hline \multirow{4}{*}{$\begin{array}{l}\text { Concentration } \\
\left(10^{9} / \mathrm{ml}\right)\end{array}$} & 1 & 10 & $1.58 \pm 0.46$ & 1.248 & 1.912 & \multirow{4}{*}{28.230} & \multirow{4}{*}{0.000} \\
\hline & 2 & 10 & $1.94 \pm 0.13$ & 1.850 & 2.030 & & \\
\hline & 3 & 10 & $0.62 \pm 0.18$ & .490 & .750 & & \\
\hline & 4 & 10 & $1.54 \pm 0.43$ & 1.232 & 1.848 & & \\
\hline \multirow{4}{*}{ Individual sperm motility (\%) } & 1 & 10 & $81.0 \pm 05.16$ & 77.31 & 84.69 & \multirow{4}{*}{18.471} & \multirow{4}{*}{0.000} \\
\hline & 2 & 10 & $71.0 \pm 03.94$ & 68.18 & 73.82 & & \\
\hline & 3 & 10 & $66.0 \pm 03.94$ & 63.18 & 68.82 & & \\
\hline & 4 & 10 & $80.0 \pm 07.45$ & 74.67 & 85.33 & & \\
\hline
\end{tabular}


Table 4: Correlations coefficients (2-tailed) of semen parameters.

\begin{tabular}{|c|c|c|c|c|c|c|}
\hline Variables & Volume & Viscosity & Mass activity & Consistency & Concentration & Individual motility \\
\hline Volume & 1 & .225 & .001 & .212 & .302 & .169 \\
\hline Viscosity & .225 & 1 & $.598^{* *}$ & $.573^{* *}$ & $.652^{* *}$ & $.340^{*}$ \\
\hline Mass activity & .001 & $.598^{* *}$ & 1 & $.584^{* *}$ & $.635^{\star *}$ & $.650^{\star *}$ \\
\hline Consistency & .212 & $.573^{* *}$ & $.584^{* *}$ & 1 & $.971^{* *}$ & $.389^{*}$ \\
\hline Concentration & .302 & $.652^{* *}$ & $.635^{* *}$ & $.971^{* *}$ & 1 & $.490^{* *}$ \\
\hline Individual motility & .169 & $.340^{*}$ & $.650^{* *}$ & $.389^{*}$ & $.490 * *$ & 1 \\
\hline
\end{tabular}

and Ajala [9] also found the variation of mass activity among the bucks. The mass activity of the sperm cells also showed gross progressive motility and high concentration with distinct dark rapid wave motions and eddies. All parameter was significantly different $(p<0.001)$ within and between the groups. The average consistency, concentration and individual motility of spermatozoa are shown in Table 3 . The consistency of B-1, B-2, B-3 and B-4 were 4.2, 4.8, 2.8 and 4.0 , respectively. The concentration of $\mathrm{B}-1, \mathrm{~B}-2, \mathrm{~B}-3$ and $\mathrm{B}-4$ were $1.58,1.94,0.62$ and $1.54 \times 10^{9}$ per $\mathrm{ml}$ of semen volume. The average percentage of individual sperm motility of B-1, B-2, B-3 and B-4 were 81, 71, 66 and 80\%, respectively. Sperm motility is the first and foremost criteria of a semen sample whether it would be selected or discarded. It is also advisable to do a motility test as soon as possible. Siddiqua, et al. [10] found that fresh sperm motility was found $80.83 \pm$ $3.53(\%)$. Our result is also partially in agreement with Dhar AC, [11]. Viscosity, mass activity, consistency, concentration and individual sperm motility were significantly $(p<0.05)$ correlated with each other (Table 4).

\section{Conclusion}

It may be concluded that the different parameters of semen analyses is varied among the bucks. Among four bucks three bucks had shown comparatively good data of semen evaluation. However, the average data of these parameters is indicated that semen of the bucks may be undertaken for further study of viability and motility before and after freezing as liquid semen.

\section{Acknowledgement}

The authors are very grateful to the Ministry of Science and Technology for the Research Contract Proposal under special allocation for Science and Technology Ministry in the financial year 2020-2021, sanction order number (SL 264, BS 264).

\section{References}

1. Paul AK, Saha NG, Pal DR. Selection of indigenous non descriptive breeding buck based on no return rate and ultrasonograhic pregnancy diagnosis of doe in Bangladesh. Adv Animal Vet Sci. 2021; 9: 10201024.

2. Amin MR, Hussain SS, Islam ABMM. Reproductive peculiarities and litter weight in different genetic groups of Black Bengal does. AsianAustralasian J Animal Sci. 2001; 14: 197-301.

3. Hussain SS. Sustainable genetic improvement of economic traits of Black Bengal goats through selective and cross breeding. Bangladesh Agricultural University Research Progress. 1999; 10: 72-80.

4. Wulster-radcliffe MC, Williams MA, Stellflug JN, Lewis GS. Semen collection from rams: AV versus a vaginal collection vial. Proceedings, Western Section. Am Soci Animal Sci. 2001; 52: 171-176.

5. Jainudeen MR, Wahid H, Hafez ESE. Sheep and goats in Reproduction in Farm Animals, E. SE Hafez, B Hafez, Eds. 1993: 172-181.

6. Sultana F, Husain SS, Khatun A, Apu AS, Khandoker MAMY. Study on buck evaluation based on semen quality and fertility. Bangladesh $\mathrm{J}$ Animal Sci. 2013; 42: 101-108.

7. Das SK, Husain SS, Amin MR, Munim T, Hoque MA, et al. Growth performance of progeny using selected Black Bengal bucks. Bangladesh J Animal Sci. 2006; 35: 27-35

8. Barbas PJ, Marques CC, Baptista CM, Vasques IM, Pereira MR, et al Reproduction in goat Sarrana breed: Seasonal and individual factors affecting fresh and frozen semen performance, in vivo and in vitro fertility. In. Animal products from the Mediterranean area. Wageningen Academic Publishers-Netherlands. 2006; 119: 337-342.

9. Raji LO, Ajala OO. Scrotal Circumference as a Parameter of Breeding age for West African Dwarf Bucks. Turkish J Agricu Food Sci Technol. 2015; 3: 668-671.

10. Siddiqua A, Islam MN, Rahman MM, Khandoker MMAY, Bari ASM. Abnormalities of semen of Black Bengal Goat in Bangladesh. Int J Nat Soc Sci. 2016; 3: 005-009.

11. Dhar AC. Normal and abnormal spermatozoa of buck semen used at commercial artificial insemination. MS thesis, Department of surgery and obstetrics, Faculty of Veterinary Science, Bangladesh Agricultural University, Mymensingh, 2007. 